\title{
ICT INTERVENTIONS FOR GIRLS: FACTORS INFLUENCING ICT CAREER INTENTIONS
}

\author{
Elena Gorbacheva \\ European Research Center for Information Systems, \\ University of Muenster, Germany \\ elena.gorbacheva@ercis.uni-muenster.de \\ Annemieke Craig \\ School of Information and Business Analytics \\ Deakin University Geelong, Australia \\ annemieke.craig@deakin.edu.au \\ Jenine Beekhuyzen \\ Deakin University, Australia \\ jenine.beekhuyzen@deakin.edu.au \\ Jo Coldwell-Neilson \\ School of Information Technology \\ Deakin University Geelong, Australia \\ jo.neilson@deakin.edu.au
}

\begin{abstract}
Intervention programs aimed at promoting study and work opportunities in the Information and Communications Technology (ICT) field to schoolgirls have been encouraged to combat a decline in the interest among girls to study ICT at school. The goal of our study is to investigate the influence of such interventions on schoolgirls' intentions to choose a career in the ICT field by analysing comprehensive survey data (n = 3711), collected during four interventions in Australia, using the Partial Least Squares method. Our study is also aimed at identifying other factors influencing ICT career intentions. We found that the attitude towards interventions has an indirect influence on ICT career intentions by affecting interest in ICT. Our results also challenge several existing theoretical studies by showing that factors that had previously been suggested as influencers were found to have little or no impact in this study, these being same-sex education and computer usage.
\end{abstract}

Keywords: Intervention, Girls and ICT, Gender diversity.

\section{INTRODUCTION}

Information and Communication Technology (ICT) is an umbrella term encompassing computing technology in a wide ranging continuum from engineering to business. ICT incorporates the disciplines of Computer Science (CS) and Information Systems (IS). According to the United Nations Commission on the Status of Women, mainstreaming a gender perspective in technology and innovation enhances social and economic equity (United Nations 2011). They argue while efforts are being made to expand access to ICT "far less attention is being paid to the extent to which women and gender concerns are shaping the regulatory and policy environments that will ultimately determine the utility and relevance of these technologies. The strategic challenge today is to ensure not only that both women and men benefit from the opportunities presented by new ICT, but also that new ICT are used to support greater socioeconomic, scientific and political equality" (UNESCO 2007). 
Practically, fewer than one-third of the vacant computing jobs expected by 2018 in the United States (U.S.) will be filled by U.S. graduates with computing degrees, which is partly due to the decreasing number of girls studying an ICT-related subject at school (Blithe 2010). Even with unprecedented demand for qualified computing workers, there has not been a significant uptake of females to fill this need. From an academic perspective, it is also argued that recruitment and retention of women in the ICT industry is particularly challenging (Trauth et al. 2009).

The call from the United Nations related to the lack of female participation in ICT in most developed countries is difficult to ignore by educators and researchers. To combat the decline in interest among girls in studying ICT at school, and ultimately at university, intervention programs for girls in ICT have been encouraged on a number of levels. The goal of our study is to investigate the influence of interventions on schoolgirls' intentions to choose a career in the ICT field and to understand other motivating factors. This leads to the following research questions (RQs):

RQ1: Do ICT intervention programs have an influence on ICT career intentions?

RQ2: What other factors influence schoolgirls' ICT career intentions?

In order to answer these questions a quantitative research study was carried out using comprehensive survey data $(n=3711)$. We could not find a well-established theoretical framework on the factors influencing girls' ICT career intentions, but there are several conceptual studies assuming a strong influence of career intentions on the actual career choice (e.g. Heinze and Hu 2009). As a starting point the model on the factors influencing girls' career choices by Adya and Kaiser (2005) was used. The data was collected during four "Go Girl, Go for IT" events in Australia in 2006, 2008, 2010 and 2012 (Events). A model showing the influence of interventions on ICT career intentions was developed and tested using Partial Least Squares (PLS) regression (Marcoulides et al. 2009).

This paper begins with a synthesis of previous research on successful interventions and an overview of studies on ICT career intentions and career choice. Introduction of the developed model showing the role of interventions in ICT career intentions is followed by the description of the applied research methodology and presentation of the results. In the concluding sections the study contribution, limitations and propositions for future research are discussed.

\section{BACKGROUND}

Although the trend across tertiary education level shows a general increase in the number of highly educated females, in specific sectors such as CS and IS, female graduates are significantly outnumbered by male graduates (European Commission 2008). The average percentage of female graduates in the science and technology field in Europe is 33\% (European Commission 2012). Similar trends are evident in Australia. Not only is female participation in computing education dropping, participation generally is also reducing. The Australian Computer Society indicates that the number of students completing ICT post-secondary qualifications has dropped by almost 30\% from approximately 19,000 completions in 2003 to just under 13,500 in 2010 (Australian Computer Society 2012). Adding to the concern are the number of females graduating with computing skills from secondary education; this number in Victoria, Australia was down dramatically from 7,315 in 2001 to 790 in 2011 (VCAA Statistics 2013). Only 96 female students (and 1208 male students) successfully completed software development at senior secondary level (VCAA Statistics 2013).

As mentioned in the previous section, interventions are one possible means to tackle this challenge. While there are intervention programs aimed at women (Panteli 2012), this paper focuses on intervention programs aimed at secondary school girls. There are strong claims that middle school is a critical period for getting girls interested in computing. According to Quesenberry and Trauth (2012), "in creating interventions to increase the representation of women in the ICT profession, it is crucial to 
develop those that influence young girls' perceptions of careers in the ICT workforce." However, Denner (2011) argues that there is little research to guide the development of interventions. Craig (2010) suggests that there is little evidence in the literature of "which interventions work best for whom" as many are implemented by volunteers who are more concerned with conducting the actual event rather than with formally evaluating the program or disseminating findings.

Bravo and colleagues (2003) provide some relevant insights into successful interventions, identifying a number of essential requirements based on their aim to change computing classroom behaviour to be a more welcoming environment for girls. To complement this list, Allison and Cossette (2007) present a summary of STEM (Science, Technology, Engineering, and Mathematics) recruitment strategies discussed in the literature and there are many similarities with the conceptualisation by Bravo and colleagues (2003). In doing a comparison of what makes a successful intervention there are important differences to highlight. Allison and Cossette (2007) argue that there is a need to create a positive and non-aggressive environment, to emphasize family and parental roles in building confidence, and encouraging mentoring relationships; these elements are not in the conceptualization by Bravo et al. (2003) who, however, identify one additional element which relates to deconstructing the essentialist view of a "natural" attraction to computers. This paper proposes that all of these elements can help to create a successful intervention and they are purposefully planned into the design of the interventions discussed in this study (Events) in a variety of ways. Thus, the ongoing design of the Events is continually guided by theory and practice relevant to gender and technology.

A number of successful interventions have been reported in the academic literature. In the U.S. the interventions based at Harvey Mudd College and Georgia Tech University are well-known among gender and computing researchers. A small liberal-arts college focusing on science and engineering, Harvey Mudd College has increased the percentage of women students in the CS major from an average near $12 \%$ to around $40 \%$ through a variety of interventions. Part of their strategy was to encourage students to attend summer research experiences (Alvarado et al. 2012). The "Georgia Computes!" intervention program targets females at different stages of the "pipeline"; they also invite secondary school students to attend summer computing camps. They report that these activities have been "overwhelmingly positive" (Bruckman et al. 2009). On evaluating the program, they found statistically significant improvements in students' attitudes about computing in response to survey questions like "Computer jobs are boring", "Girls can do computing," and "Programming is hard." Their intervention consisted of 13 events with both pre-surveys and post-surveys, and 7 of the workshops had a statistically significant improvement in participants' attitudes about computing.

Intervention strategies to increase the participation of girls in computing in Australia have also been documented in the academic literature. One example is the Digital Divas program which "aims to scaffold positive perceptions around computing in the early years of secondary school by involving female students in upbeat computing experiences over a semester" (Fisher et al. 2009; Lang et al. 2010). The curriculum for the intervention was designed to promote positive experiences in regard to selfefficacy and persistence with computing courses and career decisions. Positive outcomes were reported related to the female-only environment, the presence of role models, and the encouragement of creativity in using technology.

Reports of successful interventions however may not necessarily be published in the academic literature even though a thorough evaluation may have been completed. One example of this is the intervention conducted by the National Center for Women \& Information Technology (NCWIT) in the U.S. which reported that their "Computer Mania Day" positively influenced students' general feelings toward technology, their feelings regarding the usefulness and utility of computers and technology, and their feelings regarding women's involvement in technology. The study also found that students were more likely to take a computer course and consider a career in ICT after participating in "Computer Mania Day" (Morrell et al. 2004). 
As our study concentrates on schoolgirls who haven't made their career choice yet, we can investigate only their intentions towards a future career in the ICT field. Several studies having a similar focus and also discussing the relationship between intentions and actual career choice were found in the literature:

In the Australian context one study identified the factors influencing girls in their decisions regarding computing and future careers. It was reported that interventions have a positive effect in a way that participating girls were more positive about careers in computing and were more likely to consider enrolling in university CS courses (Anderson et al. 2008). Outside of Australia, a comparison study of African Americans and Anglo Americans examining ICT career intentions revealed that ICT selfefficacy and occupational stereotypes were related to attitudes toward ICT jobs, and that these attitudes were positively related to career intentions (Johnson et al. 2008). From a psychological perspective, BarNir et al. (2011) found that role models have a significant and positive impact on career intentions, and that gender moderated the effects and self-efficacy mediated them. Another study of Greek high school students' intentions and motivation towards and against pursuing academic studies in CS found that girls are less likely than boys to pursue a CS degree, and when they do so, it is mainly because of extrinsic reasons rather than personal interest in CS. Computer self-efficacy was found to be related to intention to study CS. The study found that a considerable proportion of Greek students opt for studying $\mathrm{CS}$, however girls constitute a minority giving credence to the phenomenon of the "shrinking pipeline" (Camp 1997) according to the authors (Papastergiou 2008).

This study uses as a starting point the Adya and Kaiser's (2005) well cited model for girls' career choices in technology fields in order to better understand girls' intentions to undertake a career in ICT. The model is based on literature to hypothesise about the future of the ICT workforce. The literature stems from a variety of disciplines, including education, psychology, sociology, CS, IS and business. The model identifies relevant factors influencing girls' career choices, which include:

- $\quad$ Social factors: Role Models and Gender Stereotypes.

- $\quad$ Structural factors: Technology Resources and Same-sex Education.

- Individual differences (based on Trauth's (2002) Individual Differences Theory of Gender and IS).

An early version of the "Go Girl, Go for IT" intervention discussed in this study was conducted in Queensland, Australia in 2000 (Craig et al. 2008) with many such events conducted in various states since then. The Event fits Courtney et al.'s (2005) classification of interventions, but not neatly. The Event lasts two days and is historically organised by an ICT industry group, which is driven by government policy. The Event is hosted and partially funded (mostly in-kind) by a local university, and volunteers participate as part of the organizing committee and as presenters on the day. The Event is aimed at building awareness about ICT career requirements and expectations, and the types of education, knowledge and skills required to work in the industry. The overall goal is to encourage participation of females in ICT studies and careers. Most of the sessions are presentations by industry professionals with PowerPoint slides and video content. The Event is attended by secondary schoolgirls between the ages of 13 and 17. Girls attend the Event either as a year-level group, a group from a computing class invited by their ICT teacher (usually female), or they volunteer to attend as individuals with interest in the Event. In any of these cases there needs to be interest in ICT within the School environment for the desire to attend an Event to be actioned. We know, from the Victorian secondary school statistics cited above, that this is not the case with declining interest in ICT in schools. Therefore, if less computing classes are being offered at secondary school, the pool of possible participants to attend the Events becomes smaller, which, unfortunately, seems to be the case and can be seen in the statistics of the Events' participants (please see the Method and Discussion sections for more details). 


\section{RESEARCH MODEL}

The data used in this study originates from a two-page questionnaire handed out to the girls attending the Event ${ }^{10}$. It has to be mentioned that the main aim of the questionnaire was to collect feedback and evaluate the Event. Therefore, the questionnaire was not intended to test a certain model or build a theory. Nevertheless, besides the attitude towards the Event, the participants were asked several additional questions, e.g. on their intentions to learn more about ICT and to work in the ICT field in the future, on the frequency and purposes of computer usage, some background information including age and school attended etc.

After having a closer look at the data available, we found enough questions to analyse ICT Career Intention (e.g. whether ICT was considered as a career option before the Event and how the Event affected it). As it was mentioned in the previous section, career intention has a strong relationship to career choice. Therefore, we decided to use the Adya and Kaiser (2005) model on the factors influencing girls' career choices as a starting point to map the information available to the model's factors:

Attitude towards the Event (Event Attitude) can be related to the model's Social Factors:

- $\quad$ One of the interventions' main goals is to tackle Gender Stereotypes.

- $\quad$ People (women or men) who give presentations at such interventions can act as Role Models for participating girls.

Information from responses to other questions can be mapped to Structural Factors:

- The Technology Resources factor can be partially tested using the questions on frequency (amount of hours per week) and purposes of computer usage (Computer Usage).

- $\quad$ The Same-sex Education factor can be tested using the information about the schools attended by the respondents.

Based on the propositions made in the Adya and Kaiser (2005) model and the information available in the questionnaire, some initial hypotheses were built on possible factors influencing ICT Career Intention:

H1: Favourable Event Attitude has a positive influence on ICT Career Intention

H2: Frequency of computer usage (Computer Usage) has a positive influence on ICT Career Intention

H3: Usage of computers for building web sites or programming (Computer Usage) has a positive influence on ICT Career Intention

H4: Sex-segregation of school environment (Same-sex Education) has a positive influence on ICT Career Intention

H5: Interest in ICT (ICT Interest) has a positive influence on ICT Career Intention

H6: Intention to find out more about ICT after the Event (ICT Intention to Learn) has a positive influence on ICT Career Intention

${ }^{10}$ Please contact the authors for more information on the questionnaire used in the study. 
In order to test whether any dependencies between these constructs exist at all, associations between all the variables were tested and, depending on a variable type, several association coefficients were calculated. Phi coefficients $(\varphi)$ were calculated for binary nominal variables (those derived from 'Yes/No' questions) and the significance of their associations was checked with Chi-Square Tests (Cramér 1946). For ordinal variables (those having a clear ordering) Spearman's correlation coefficients ( $\rho)$ were calculated (e.g. Lehman and Rourke 2005). Finally, in order to reveal an existence of association between nominal and ordinal variables Kruskal-Wallis method was used (Kruskal and Wallis 1952) and Cramér's V $\left(\varphi_{c}\right)$ measure of association was calculated (Cramér 1946).

We found that ICT Career Intention has strong positive association with ICT Interest and ICT Intention to Learn and moderate positive relationship with Event Attitude. Moreover, we found that ICT Interest has strong significant associations with both Event Attitude and ICT Intention to Learn (please see the Results section for more details). No strong relationships were found between ICT Career Intention and Computer Usage or Same-sex Education, which contradicts the propositions made in the Adya and Kaiser (2005) model. Thus, hypotheses $H 2, H 3$, and $H 4$ had to be rejected and not taken into consideration for building a research model.

Based on the results, we suggest that both ICT Interest and ICT Intention to Learn influence ICT Career Intention. We also assume that Event Attitude has an influence on ICT Interest, which, in turn affects ICT Intention to Learn. Our Research Model for further testing is presented in Figure 1.

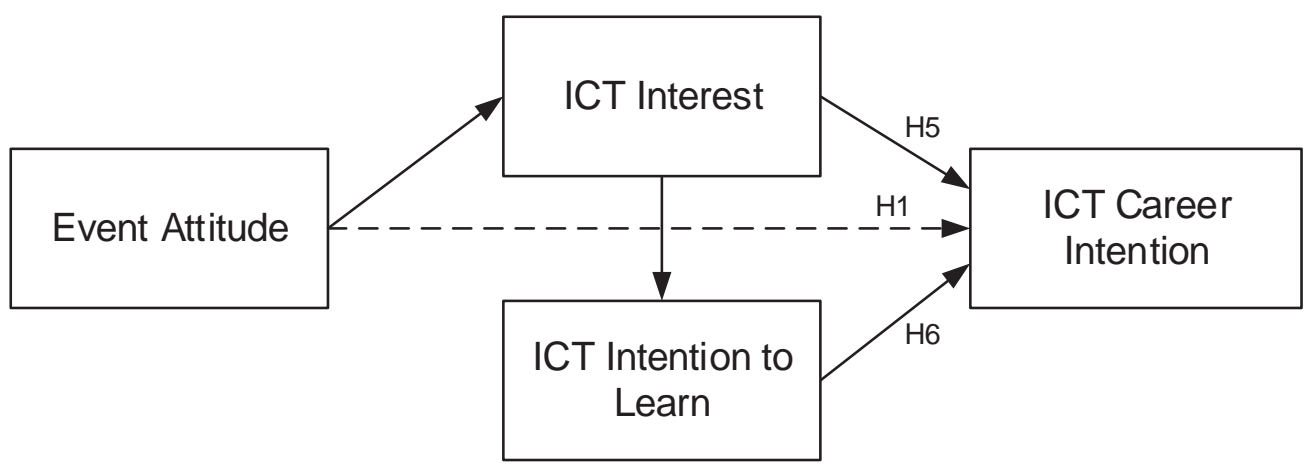

Figure 1: Research Model

\section{METHOD}

The questionnaire was adapted from a similar one used at another intervention and pre-tested by three people. In order to motivate girls to fill in a questionnaire, a show bag full of gifts provided by participating organizations was given in return for a completed questionnaire. This was a highly successful strategy and the absolute majority of the Event participants took part in the survey. As a result, in total 4168 responses were received: 1668 in 2006, 1070 in 2008, 792 in 2010, and 638 in 2012. Such a decrease in the number of responses after 2006 occurred since fewer girls were participating in the Events. The two main reasons here are administrative issues (there was little chance to schedule the Events in 2008-2012 to fit the schools calendar) and a decrease in the number of ICT teachers who usually organised the trips (please see the Discussion section for more details). In the questionnaire we asked both open-ended and closed-ended questions, but for this study we concentrated on the closed-ended questions in order to test the proposed hypotheses. 
Once initial responses were coded using MS Excel, we first introduced a construct categorizing girls according to their ICT Career Intention using SPSS 21 software. Initially we considered using Digital Natives, Digital Immigrants and Digital Neglecters to represent the categories but realized that at least the first two terms are very well established in meaning and use. According to Prensky's (2001) seminal work, Digital Natives are those born in the digital era and Digital Immigrants are those who have adopted technology. Since the girls participating in the Events are all Digital Natives (due to their age) this terminology was not useful. Further investigation revealed the Anderson et al. (2008) model which differentiates between those who take technology subjects at school and those who do not and called them Takers and Non Takers respectively. The Anderson model suggests that being a Taker or a Non Taker directly affects future participation in ICT professions. This proved to be a useful starting point. However, studying a subject at school does not necessarily imply intent to have a career in the area nor does the lack of subject imply a lack of interest in a future career in the area. For example, if a student is studying mathematics there is only a slim chance that they would also be considering a career as a mathematician. However, there are no school subjects which naturally lead or imply, in a similar way, an interest in a career in teaching.

Based on this initial analysis, we developed a new model based on intent to consider ICT as a career option rather than on current study habits. The three categories are based on those proposed by Anderson et al. (2008) and reflect the girls' intent to consider an ICT career before and after the Event. These three categories are:

1. ICT Career Current Non Takers (Non Takers): girls who did NOT consider ICT as a career option neither before nor after the Event.

2. ICT Career Newcomers (Newcomers): girls who did NOT consider ICT as a career option before the Event, but changed their minds during the Event.

3. ICT Career Takers (Takers): girls who considered ICT as a career option both before and after the Event. We consider this group to be more robust in their ICT Career Intention than Newcomers.

We then cleansed the data: The 320 cases containing missing data to any of the questions related to our target variable ICT Career Intention were removed. A category of cases with positive responses on ICT as a career option before the Event, but negative - after the Event (meaning that the Event had a negative influence on ICT Career Intention) was very low in comparison to the other three above-mentioned categories $(n=136)$. Therefore, it was not taken into consideration in the current study and left for future investigation. Moreover, inconsistent responses to several control questions were marked as missing and then for each case the total share of missing information was calculated. One case contained more than $35 \%$ of missing responses and was removed. The resulting study sample containing 3711 cases is examined in Table 1.

As mentioned in the previous section, the initial hypotheses were analysed employing association coefficients and SPSS 21 software. The developed model was further tested using the Partial Least Squares (PLS) method using SmartPLS 2.0 (Ringle et al. 2005). The PLS algorithm was chosen because it has no distribution assumptions for the measured variables and is a relatively flexible forecasting method. All constructs were modelled using reflective indicators. The analysed data (involved in the developed model) contains $13.2 \%$ missing values, which were treated using the Mean Replacement algorithm.

\section{RESULTS}

Newcomers is the largest category in the sub-samples for each Event and in the resulting sample; Non Takers is consistently the smallest category (see Table 1). Two conclusions arise from this statistics: 
first, among secondary schoolgirls (at least those participating in interventions) there are very few who neglect ICT, the absolute majority consider this field as favourable for future studies and career. Second, the Event motivated $40 \%$ of participating girls to start considering ICT as a career option, which was not the case before the Event.

\begin{tabular}{l|r|r|r|r|r|r|r|r}
\hline & \multicolumn{2}{|c|}{ Non Takers } & \multicolumn{2}{c|}{ Newcomers } & \multicolumn{2}{c|}{ Takers } & \multicolumn{2}{c}{ Total (Year) } \\
\hline Year & $\mathrm{n}$ & $\%$ & $\mathrm{n}$ & $\%$ & $\mathrm{n}$ & $\%$ & $\mathrm{n}$ & $\%$ \\
\hline 2006 & 462 & $30.9 \%$ & 540 & $36.1 \%$ & 495 & $33.0 \%$ & 1497 & 100 \\
2008 & 251 & $26.9 \%$ & 366 & $39.2 \%$ & 317 & $33.9 \%$ & 934 & 100 \\
\hline 2010 & 124 & $17.3 \%$ & 333 & $46.4 \%$ & 260 & $36.3 \%$ & 717 & 100 \\
2012 & 108 & $19.2 \%$ & 247 & $43.9 \%$ & 208 & $36.9 \%$ & 563 & 100 \\
\hline Total & 945 & $25.5 \%$ & 1486 & $40.0 \%$ & 1280 & $34.5 \%$ & 3711 & 100 \\
\hline
\end{tabular}

Table 1. Study Sample and Distribution of ICT Career Intention Categories

The above-mentioned analysis of association coefficients between all variables has led to the following results:

1. Event Attitude has positive strong association with the ability of the event to bring a positive feeling about careers in ICT $(1 \mathrm{a})\left(\varphi_{\mathrm{c} 1}=0.466\right)$ and a moderate association with the attitude towards presenters speaking about their experiences in ICT $(1 \mathrm{~b})\left(\varphi_{\mathrm{c} 2}=0.244\right)$. These constructs are also strongly positively correlated with each other $\left(\varphi_{3}=0.420\right)$.

2. The ICT Interest construct is formed by two items: the interest in ICT after attending the event (2a) and an interest in ICT subjects at school (2b), which have strong significant correlation with each other $\left(\rho_{4}=0.607\right)$ and with Event Attitude $\left(\rho_{5}=0.587\right.$ and $\rho_{6}=0.415$ respectively).

There is also a strong positive association between $2 \mathrm{a}$ and $\mathrm{a}\left(\varphi_{\mathrm{c} 7}=0.531\right)$.

3. The ICT Intention to Learn construct is again formed by two items, namely an intention to find out more about ICT (3a) and an intention to select ICT based subject at school next year ( $3 b)$, which have strong significant associations between each other $\left(\varphi_{8}=0.609\right), 2 \mathrm{a}\left(\varphi_{\mathrm{c} 9}=0.698\right.$ and $\varphi_{\mathrm{c} 10}=0.622$ respectively), as well as $2 \mathrm{~b}\left(\varphi_{\mathrm{c} 11}=0.445\right.$ and $\varphi_{\mathrm{c} 12}=0.484$ respectively).

Event Attitude has strong positive associations with $3 \mathrm{a}\left(\varphi_{\mathrm{c} 13}=0.482\right)$ and $3 \mathrm{~b}\left(\varphi_{\mathrm{c} 14}=0.379\right)$. There is also a strong positive association between $3 \mathrm{a}$ and a $\left(\varphi_{15}=0.351\right)$.

4. ICT Career Intention (our target dependent construct) has strong positive associations with both the ICT Interest and the ICT Intention to Learn constructs, namely with $2 \mathrm{a}\left(\varphi_{\mathrm{c} 16}=0.614, \varphi_{\mathrm{c} 17}=0.448\right), 2 \mathrm{~b}$ $\left(\varphi_{\mathrm{c} 18}=0.364, \varphi_{\mathrm{c} 19}=0.374\right), 3 \mathrm{a}\left(\varphi_{20}=0.609, \varphi_{21}=0.390\right)$, and $3 \mathrm{~b}\left(\varphi_{22}=0.528, \varphi_{23}=0.390\right)$. ICT Career Intention also has a moderate positive association with Event Attitude $\left(\varphi_{\mathrm{c} 24}=0.381, \varphi_{\mathrm{c} 25}=0.212\right)$.

In order to test the developed model (see Figure 1), we exploited the PLS path modelling algorithm (Marcoulides et al. 2009), which includes the following steps:

1. Significance of the relationships between the items and their corresponding constructs, namely between ICT Career Intention and its two items, ICT Interest and $2 \mathrm{a}, 2 \mathrm{~b}$, as well as ICT Intention to Learn and 3a, 3b, were tested. The Event Attitude construct has only one item, so the test is not relevant for it. The test was performed by bootstrapping the original dataset with 500 samples. The results show 
that the $t$-values were far above 1.96, which indicated their significance at $p$-value less than 0.01 (see Table 2).

\begin{tabular}{lll}
\hline & $t$-Statistics & Path Coefficients \\
\hline ICT Interest --> ICT Career Intention & 3.059 & 0.33 \\
ICT Intention to Learn --> ICT Career Intention & 3.341 & 0.39 \\
ICT Interest --> ICT Intention to Learn & 12.337 & 0.65 \\
Event Attitude --> ICT Interest & 7.960 & 0.57 \\
\hline
\end{tabular}

Table 2. t-Statistics and Path Coefficients

2. The strength of influence of items on corresponding constructs (again, relevant only for multiple item constructs ICT Career Intention, ICT Interest and ICT Intention to Learn), as well as the strength of influence of the related constructs on each other were checked. All relevant factor loadings in the outer model are above 0.71 and, therefore, satisfy the requirement of discriminant validity (Fornell and Larcker 1981). All path coefficients in the inner model are also quite strong, especially between ICT Interest and ICT Intention to Learn (0.65), as well as between Event Attitude and ICT Interest (0.57) showing very strong direct influence between these constructs (see Table 2).

3. The coefficient of determination $\left(\mathrm{R}^{2}\right)$ of our target variable ICT Career Intention, i.e. the proportion of variability in a data set that is explained by the statistical model (Steel and Torrie 1980), is quite high (42.3\%) (see Table 3). As Event Attitude is not predicted by any other variable in our model, its $\mathrm{R}^{2}$ equals zero.

\begin{tabular}{|c|c|c|c|c|c|c|c|c|c|}
\hline & \multirow{3}{*}{$R^{2}$} & \multirow{3}{*}{$\begin{array}{l}\text { Cronbach's } \\
\text { Alpha }\end{array}$} & \multicolumn{7}{|c|}{ Cross Loadings } \\
\hline & & & \multicolumn{2}{|c|}{$\begin{array}{l}\text { ICT Career } \\
\text { Intention }\end{array}$} & \multicolumn{2}{|c|}{ ICT Interest } & \multicolumn{2}{|c|}{$\begin{array}{l}\text { ICT Intention to } \\
\text { Learn }\end{array}$} & \multirow[t]{2}{*}{$\begin{array}{l}\text { Event } \\
\text { attitude }\end{array}$} \\
\hline & & & $1 \mathrm{a}$ & $1 b$ & $2 \mathrm{a}$ & $2 b$ & $3 a$ & $3 b$ & \\
\hline $\begin{array}{l}\text { ICT Career } \\
\text { Intention }\end{array}$ & 0.42 & 0.60 & 0.89 & 0.79 & 0.60 & 0.30 & 0.50 & 0.54 & 0.35 \\
\hline ICT Interest & 0.32 & 0.60 & 0.52 & 0.45 & 0.94 & 0.72 & 0.55 & 0.58 & 0.57 \\
\hline $\begin{array}{l}\text { ICT } \\
\text { Intention to } \\
\text { Learn }\end{array}$ & 0.42 & 0.68 & 0.59 & 0.40 & 0.68 & 0.34 & 0.86 & 0.88 & 0.44 \\
\hline $\begin{array}{l}\text { Event } \\
\text { Attitude }\end{array}$ & 0 & 1 & 0.37 & 0.21 & 0.59 & 0.30 & 0.34 & 0.42 & 1 \\
\hline
\end{tabular}

Table 3. Coefficients of Determination, Cronbach's Alpha and Cross Loadings

4. The internal consistency reliability (ICR) of each construct was assessed by Cronbach's alpha test, which is 0.6 or above and, therefore, can be considered as acceptable (Hinton et al. 2005, see Table 3).

5. The Cross Loadings Coefficients test checks whether the items load the most to the related latent variables, which is fulfilled in our model: the items $1 \mathrm{a}$ and $1 \mathrm{~b}$ load the most to ICT Career Intention, $2 \mathrm{a}$ and $2 \mathrm{~b}$ - to ICT Interest and $3 \mathrm{a}$ and $3 \mathrm{~b}$ - to ICT Intention to Learn. As Event Attitude is the single- 
item construct, its loading equals 1 . It is important that the difference between an item loading to a related latent variable is at least 0.2 more than loadings to any unrelated latent variable, which is true in our case (see Table 3).

Thus, all relationship in the model are statistically significant and strong, all the constructs built have high ICR. Therefore, our hypotheses H5 and H6 that ICT Interest and ICT Intention to Learn have a positive influence on ICT Career Intention are validated (see Table 4). The hypothesis HI, that the Event Attitude has a positive influence on ICT Career Intention is partially validated, as an indirect influence via ICT Interest was observed.

\begin{tabular}{l|l}
\hline Validated & Rejected \\
\hline H1 (indirect influence), H5, H6 & H2, H3, H4 \\
\hline
\end{tabular}

Table 4. Hypotheses Testing Results

Based on the results achieved, we can argue that interventions have an indirect positive influence on ICT career intentions (RQ1) by directly influencing the general interest in ICT, which, in turn, has a direct positive influence on ICT career intentions (RQ2). Another factor derived from the data available, which positively influences ICT career intentions is ICT Intention to Learn, the intention to find out more about ICT after the Event (RQ2).

\section{LIMITATIONS AND FUTURE RESEARCH}

Our study has a number of limitations, which are also the subject for future research. First of all, it is data-driven, not model-driven. The analysed questionnaire was initially developed to evaluate the Event, enabling organisers to improve the running of the program; not to test our research model. Therefore, for future Events we will perform a major revision of the questionnaire and will include more questions to test other factors, which might have a significant influence on ICT career intentions. The new set of questions will be informed by other comparable studies and theoretical propositions in the literature (such as the model of Adya and Kaiser, 2005): e.g. more attention would be given to the influence of role models and gender stereotypes coming from family, peer group, media and teachers. Another important set of questions should address the Newcomers category why they did not consider ICT as a career option before the Event.

The updated questionnaire should also contain more closed questions and fewer open-ended questions. The reason for doing this is that some of the schoolgirls fill in the open questions very reluctantly more than a quarter of responses to the open-ended questions are missing (25.4\%) compared to $9.5 \%$ missing values for the closed-ended questions. We have already discussed that some open questions can easily be transferred to closed ones to avoid biased interpretation of the responses, e.g. a tick box for indicating a favourite session instead of free text. The improved questionnaire can then be used to evaluate similar interventions for girls in other countries forming a cross-cultural comparative study.

Second, more empirical evidence is required to confirm our assumption that career intentions lead to career choice. Up to now we could only find conceptual propositions in the literature. A longitudinal study of the girls who participated in one of the Events would be very valuable. Here we also assume that an intention to choose a career in ICT is a necessary, but not sufficient, factor for making a final choice in favour of this field for studies and work. We call for empirical testing of other possible factors influencing ICT career choice taking for example the Adya and Kaiser (2005) model as a basis. Such a survey could be enhanced by involving females who already study or work in the ICT field. 


\section{CONCLUSION}

There are strong arguments that having diversity in business and technology decision-making in organizations enables new kinds of innovation and is significantly beneficial, both economically and through increased productivity (e.g. Craig et al. 2013). According to NCWIT, gender diversity is of importance to the computing industry as diversity: "expands the employee pool; improves the bottom line, enhances innovation; [and] promotes equality" (Dubow 2011). However in the ICT field women continue to be underrepresented (e.g. European Commission 2012). This article also highlights the lack of skilled personnel that will be available to fill the needs in the ICT industry in the next decade (e.g. Ashcraft and Blithe 2010).

One possible strategy to tackle these challenges is to invite schoolgirls to attend events aimed at promoting ICT education and career opportunities. This paper critically reflects and evaluates the contribution of one such Event, namely "Go Girl, Go for IT", and investigates its influence on ICT career intentions using quantitative analysis of survey data with PLS method. The results of our survey confirm the success of the Event with more than $90 \%$ of the respondents reporting a positive feeling about careers in ICT after the Event. At the same time, we would like to raise a concern that we observed a constant decrease in the amount of Event participants in 2006-2012. As mentioned earlier, the girls are usually invited by their ICT teacher, but the trend is that each year there are fewer teachers who can do it, as less computing classes are being offered at secondary school. We call for action to improve this situation, as our results show that interest in ICT subjects at school is crucial in forming intentions to choose ICT as a future career.

In our study we introduced three categories of girls' attitude towards careers in ICT (Non Takers, Newcomers and Takers). Based on the findings, we argue that if we can influence Newcomers to become Takers, then we may shift the cycle of non-participation in ICT. This is an iterative cycle in that we propose that Newcomers can become Takers through continuous inspiring interventions and many positive messages about women in ICT from a range of sources and within a range of environments.

We also show that interventions have significant influence on interest in ICT which, in turn, affects ICT career intentions. Contradictory to the Adya and Kaiser (2005) model, we uncovered that same-sex education environments, frequency of computer usage, and the purpose of usage (e.g. for building websites or programming) do not have an influence on ICT career intentions.

We need many different intervention programs for schoolgirls to engage in at different times in their young lives to give them many positive experiences and a wide variety of information about working with technology. Fisher and colleagues (2009) identify impacts on the sphere of influence and the Event discussed in this study is just one such sphere. We would like to further understand ICT career intentions and plan to test the developed model at future Events and other interventions. We also argue that in part due to the voluntary nature of these events, some limitations are evident. It is important to note that organisers and presenters are not paid directly for their efforts and are often not financially supported for their involvement in the event. This is in part due to the lack of continual support from one-well funded organization like the National Science Foundation or NCWIT in the U.S. Such events rely on industry funding and the volunteer time of those involved. As such, it is argued that more consistent and substantial funding could aid the better organisation, planning and implementation of these interventions.

\section{REFERENCES}

Adya, M., and Kaiser, K. M. 2005. "Early determinants of women in the IT workforce: a model of girls' career choices," Information Technology \& People (18:3), pp. 230-259. 
Allison, C., and Cossette, I. 2007. "Theory and Practice in Recruiting Women for STEM Careers," in Proceedings of the WEPAN 2007 Conference, Copyright 2007, WEPAN-Women in Engineering Programs and Advocates Network, Lake Buena Vista, Florida.

Alvarado, C., Dodds, Z., and Libeskind-Hadas, R. 2012. "Increasing women's participation in computing at Harvey Mudd College," ACM Inroads (3:4)New York, NY, USA: ACM, pp. 5564.

Anderson, N., Lankshear, C., Timms, C., and Courtney, L. 2008. "“Because it's boring, irrelevant and I don't like computers': Why high school girls avoid professionally-oriented ICT subjects," Computers \& Education (50:4), pp. 1304-1318.

Australian Computer Society. 2012. “2012 Australian ICT Statistical Compendium,” Canberra.

BarNir, A., Watson, W. E., and Hutchins, H. M. 2011. "Mediation and moderated mediation in the relationship among role models, self-efficacy, entrepreneurial career intention, and gender," Journal of Applied Social Psychology (41:2), pp. 270-297.

Blithe, S. 2010. "Women in IT: The facts," National Center for Women \& Information Technology ( NCWIT ), Boulder, CO.

Bravo, M. J., Gilbert, L. A., and Kearney, L. K. 2003. "Interventions for Promoting Gender Equitable Technology Use in Classrooms," Teacher Education Quarterly (30:4), pp. 95-110.

Bruckman, A., Biggers, M., Ericson, B., Mcklin, T., Dimond, J., Disalvo, B., Hewner, M., Ni, L., and Yardi, S. 2009. "Georgia Computes !': Improving the Computing Education Pipeline," in Proceedings of the Special Interest Group on Computer Science Education (SIGCSE'09), , pp. 86-90.

Camp, T. 1997. "The incredible shrinking pipeline," Communication of the ACM (40:10), pp. 103-110.

Coldwell, J., Fisher, J., and Lang, C. 2013. "The Silicon Ceiling: Women managers and leaders in ICT in Australia," in Women and Mangement: Global issues and promising Solutions, (Vol. 2), pp. 177-200.

Courtney, L., Timms, C., Lankshear, C., and Anderson, N. 2005. "Establishing pathways for girls in ICT: The search for strategies to achieve balance in Queensland," Journal of the Association of Women Educators (14:3), pp. 14-19.

Craig, A. 2010. Attracting women to computing: A framework for evaluating intervention programmes, Saarbrücken, Germany: VDM Verlag Dr Muller Aktiengesellschaft \& Co. KG.

Craig, A., Lang, C., and Fisher, J. 2008. "Twenty Years of Girls into Computing Days: Has It Been Worth the Effort?," Journal of Information Technology Education (7).

Cramér, H. 1946. Mathematical Methods of Statistics, Princeton: Princeton University Press.

Denner, J. 2011. "What Predicts Middle School Girls' Interest in Computing? What Predicts Middle School Girls ' Interest in Computing?," International Journal of Gender, Science and Technology (3:1), pp. 54-69.

Dubow, W. 2011. "NCWIT Scorecard: A report on the status of women in information technology," Boulder.

European Commission. 2008. "Women in ICT: Status and the way ahead,” Brussels.

European Commission. 2012. "She Figures 2012: Gender in Research and Innovation - Statistics and Indicators,” Brussels.

Fisher, J., Lang, C., Forgasz, H., and Craig, A. 2009. "Digital divas: Working to change students' perceptions about ICT courses and careers," Curriculum Leadership (7:31). 
Fornell, C., and Larcker, D. F. 1981. "Structural Equation Models with Unobservable Variables and Measurement Error: Algebra and Statistics," Journal of Marketing Research (18:3), pp. 382388.

Heinze, N., and Hu, Q. 2009. "Why college undergraduates choose IT: a multi-theoretical perspective," European Journal of Information Systems (18:5)Palgrave Macmillan, pp. 462-475.

Hinton, P., Brownlow, C., and McMurray, I. 2005. SPSS Explained 2nd Edition, Routledge Chapman \& Hall.

Johnson, R. D., Stone, D., and Nichole Phillips, T. 2008. "Relations among ethnicity, gender, beliefs, attitudes, and intention to pursue a career in Information Technology," Journal of Applied Social Psychology (38:4), pp. 999-1022.

Kruskal, W. H., and Wallis, W. A. 1952. "Use of Ranks in One-Criterion Variance Analysis,” Journal of the American Statistical Association (47:260), pp. 583-621.

Lang, C., Craig, A., Fisher, J., and Forgasz, H. 2010. "Creating Digital Divas - Scaffolding Perception Change Through Secondary School and University Alliances," in ITiCSE'10 Proceedings of the fifteenth annual conference on Innovation and technology in computer science education, New York, NY, pp. 38-42.

Lehman, A., and Rourke, N. O. 2005. JMP for Basic Univariate and Multivariate Statistics A Step-byStep Guide, Analysis, , p. 481.

Marcoulides, G., Chin, W., and Saunders, C. 2009. "A Critical Look at Partial Least Squares Modeling," MIS Quarterly (33:1), pp. 171-175.

Morrell, C., Cotten, S., Sparks, A., Spurgas, A., and UMBC Graduate. 2004. "Computer Mania Day: An effective intervention for increasing youth's interest in technology.," University of Maryland/Baltimore County.

Panteli, N. 2012. "A community of practice view of intervention programmes: the case of women returning to IT," Information Systems Journal (22:5), pp. 391-405.

Papastergiou, M. 2008. “Are Computer Science and Information Technology still masculine fields? High school students' perceptions and career choices," Computers \& Education (51:2), pp. 594608.

Prensky, M. 2001. "Digital Natives, Digital Immigrants Part 1,” On the Horizon, , pp. 1-6.

Quesenberry, J. L., and Trauth, E. M. 2012. "The (dis)placement of women in the IT workforce: an investigation of individual career values and organisational interventions," Information Systems Journal (22:6), pp. 457-473.

Ringle, C. M., Wende, S., and Will, S. 2005. "SmartPLS 2. Hamburg: SmartPLS, Available at http://www.smartpls.com,".

Steel, R. G. D., and Torrie, J. H. 1980. Principles and Procedures of Statistics: a Biometrical Approach, (Second Ed.) New York: McGraw-Hill Kogakusha.

Trauth, E. M. 2002. "Odd girl out: an individual differences perspective on women in the IT profession," Information Technology \& People (15:2), pp. 98-118.

Trauth, E. M., Quesenberry, J. L., and Huang, H. 2009. "Retaining women in the U.S. IT workforce: theorizing the influence of organizational factors," European Journal of Information Systems (18:5)Palgrave Macmillan, pp. 476-497.

UNESCO. 2007. "Science, Technology and Gender: An International Report," Paris, France.

United Nations. 2011. "Mainstreaming a Gender Perspective in Science, Technology and Innovation Policy," . 
VCAA Statistics. 2013. "Senior secondary certificate statistical information," Victorian Curriculum and Assessment Authority. Retrieved 5/8/2013, from http://www.vcaa.vic.edu.au/Pages/vce/statistics/subjectstats.aspx .

\section{ACKNOWLEDGEMENTS}

We would like to thank all the volunteers who organized the "Go Girl, Go for IT" events and, consequently, all the girls who attended and made this study possible. We also gratefully acknowledge the support of the sponsors, speakers and the ICT teachers who motivated schoolgirls to participate in the "Go Girl, Go for IT" events. We also gratefully acknowledge Dr Armin Stein for his ongoing support of the project.

An earlier version of this paper was presented at the Australasian Conference on Information Systems (ACIS) 2013 in Melbourne, Australia. 